\title{
Androgen secreting giant adrenocortical carcinoma with no metastases: A case report and review of the literature
}

\author{
Fatih Uruc, MD; Ahmet Urkmez, MD; Ozgur Haki Yuksel, MD; Aytac Sahin, MD; Ayhan Verit, MD
}

Fatih Sultan Mehmet Research and Training Hospital, Department of Urology, Içerenkoy/Atasehir, Istanbul, Turkey

Cite as: Can Urol Assoc J 2015;(9-10):E644-7. http://dx.doi.org/10.5489/cuaj.2867 Published online September 9, 2015.

\section{Abstract}

Functional adrenocortical carcinoma (ACC) is a very rare disease with a poor prognosis. Over half (60\%) of ACCs bigger than $6 \mathrm{~cm}$ synthesize hormones; hormone-secreting ACCs generally include virilization, feminization or Cushing syndrome. Besides, $82 \%$ of ACCs are metastatic at the time of diagnosis. While a 48 -year-old female patient was examined for abdominal pain and flushing, we detected a non-metastasizing mass $(23 \times 18 \times 16 \mathrm{~cm})$ in the adrenal lodge. The mass was extracted en bloc during open exploration and its histopathology was reported as ACC. We review the literature and report the largest androgen-producing, clinically silent ACC mass cited in the literature so far.

\section{Introduction}

Adrenocortical carcinoma (ACC) is a very rare malignant tumour $(0.02 \%$ of all cancer types); its incidence in adults is $1 / 1.7$ million. ${ }^{1,2}$ ACC demonstrates a bimodal distribution and its incidence peaks before 5 years old and between 40 and 50 years old. ${ }^{3}$ Most of ACCs are sporadic, but its congenital and familial types can be encountered. ${ }^{4,5}$ It is seen 1.5 times more frequently in women. ACCs are larger than benign adrenal masses and measure about 10 to $12 \mathrm{~cm}$. ACCs accounts for $2 \%$ of adrenal tumours that are $4 \mathrm{~cm}$ or less, $6 \%$ of tumors that are 4.1 to $6 \mathrm{~cm}$, and $25 \%$ of tumours that are greater than $6 \mathrm{~cm} .{ }^{6}$ On the other hand, over $90 \%$ of ACCs are bigger than $6 \mathrm{~cm}$. They weigh 0.1 to $1.0 \mathrm{~kg}$. Adrenal masses divide into 2 groups: hormone-secreting tumours and non-secreting tumours. About $60 \%$ of ACCs synthesize hormones. Hormone-secreting ACC presents itself with manifestations of virilization, feminization or Cushing syndrome; hormone-non-secreting ACCs are usually diagnosed incidentally. ${ }^{7,8}$ Even if the tumour is extirpated completely, recurrence or distant metastases are encountered in many patients. ${ }^{9}$ For staging, the ENSAT (European Network for the Study of Adrenal Tumours) classification is used. ${ }^{4}$ Five-year survival rates in stage I, II and III disease are $84 \%$, $63 \%$ and $53 \%$, respectively; the stage IV 1 -year survival rate is nearly $15 \% .^{10,11}$ In early stage ACC, age $<40$, absence of lymph node involvement and distant metastases are positive prognostic factors, while tumours larger than $12 \mathrm{~cm}$ diameter carry adverse prognostic factors. ${ }^{12}$

Negative surgical margins increase survival rates independent from other factors. Though spontaneous regression has been reported, $82 \%$ of ACCs are metastatic at diagnosis. It metastasizes most frequently to lungs ( $71 \%)$, lymph nodes $(68 \%)$, liver (42\%), bones $(20 \%)$, and inferior vena cava $(20 \%) . .^{13}$ The only curative treatment is surgical resection. Survival rates of inoperable patients are very low. In the systemic treatment of ACC, despite its toxicity and lower response rates, an adrenolytic agent mitotane can be used. ${ }^{14,15}$ We report a case of the largest but clinically silent, androgen-producing, non-metastasizing ACC mass.

\section{Case report}

During ultrasonographic examination of a 48-year-old female patient with abdominal pain and flushing, we detected a hypoechoic solid adrenal mass. Her medical history did not reveal any comorbid disease or regular use of any medication. On physical examination, a mass was palpated at the left hypochondriac region and she had minimally frontal balding. Her average blood pressure was 130/80 $\mathrm{mmHg}$ on 24-hour ambulatory blood pressure monitoring. Her serum aldosterone, potassium, renin, 24-hour urine metanephrine levels, and dexamethasone suppression test results were within normal limits. Only levels of serum total testosterone and dehydroepiandrosterone sulfate (DHEA-S) were measured $(1.28 \mathrm{ng} / \mathrm{mL}$ and $>1500 \mu \mathrm{g} / \mathrm{dL}$, respectively) (Table 1$)$. A magnetic resonance image (MRI) demonstrated a heterogeneously enhancing mass lesion in the left adrenal lodge with cystic-necrotic components measuring $208 \mathrm{~mm} \times 138 \mathrm{~mm}$ 


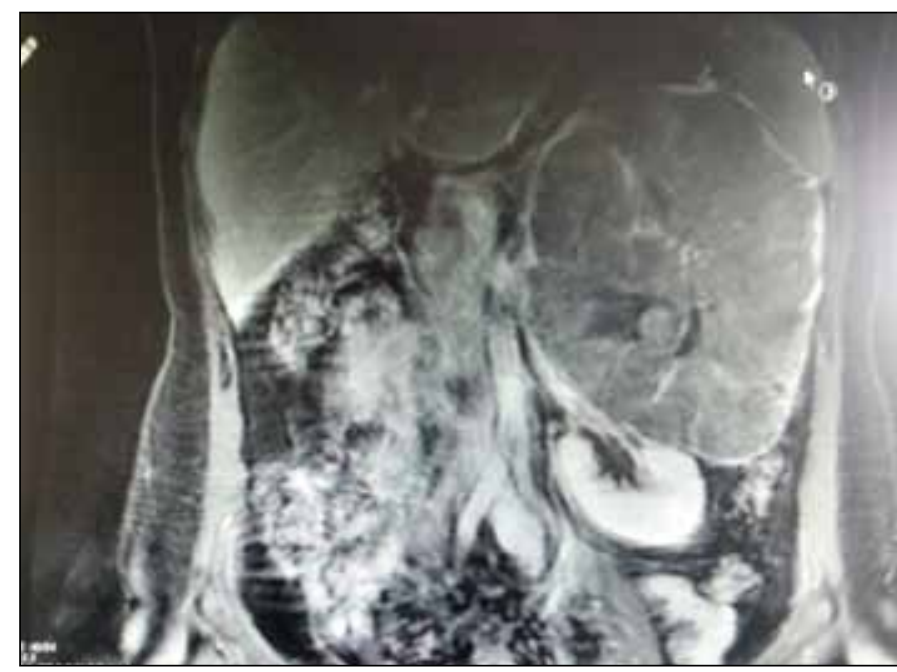

Fig. 1. Contrast-enhanced magnetic resonance image: Coronal plane.

and deplacing the pancreas and splenic vein superiorly and left kidney inferiorly (Fig. 1, Fig. 2). Positron emission tomography-computed tomography (PET/CT) was performed for metastatic workup and pathologic 18-fluorodeoxyglucose (FDG) uptake was not encountered. The patient was referred to the department of endocrinology; preoperative nifedipine at daily oral doses of $60 \mathrm{mg}$ were initiated. Through a modified Chevron incision, we explored the surgical field, reached the mass and extirpated it en bloc (Fig. 3). Her perioperative blood pressure values remained stable. The histopathology revealed an encapsulated mass with smooth contours weighing 1300 gr, with dimensions of $23 \times 18 \times 16 \mathrm{~cm}$, which was identified as adrenocortical carcinoma demonstrating increased mitotic activity (Fig. 4). Immunohistochemically, it was stained positively with vimentin, synaptophysin and cytokeratin (Fig. 5). Its mitotic and $\mathrm{Ki}-67$ proliferation indices were reported $56 / 50$ and $11 \%$ to $13 \%$, respectively. During her follow-up visits, DHEA-S and total testosterone levels

\begin{tabular}{|c|c|c|c|}
\hline & $\begin{array}{c}\text { Pre- } \\
\text { operative }\end{array}$ & $\begin{array}{c}\text { Post- } \\
\text { operative }\end{array}$ & Range \\
\hline DHEA-SO4 (ug/dL) & $>1500$ & 144.6 & $56-283$ \\
\hline Cortisol (ug/dL) & 9.3 & 9.1 & $3.7-19.4$ \\
\hline $\begin{array}{l}\text { Metanephrine } \\
\text { (ug/24h urine) }\end{array}$ & 61.37 & & $52-341$ \\
\hline $\begin{array}{l}\text { Normetanephrine } \\
\text { (ug/24h urine) } \\
\text { VMA (mg/24h urine) }\end{array}$ & $\begin{array}{c}323.32 \\
3.8\end{array}$ & & $\begin{array}{c}88-444 \\
3-9\end{array}$ \\
\hline Aldosterone (ng/dL) & 20.9 & & $7-30$ \\
\hline Renin (ng/mL/hour) & 4.24 & & $(2.9-10.8)$ \\
\hline $\begin{array}{l}\text { Total testosterone } \\
\text { (ng/mL) } \\
\text { Prolactin (ng/dL) } \\
\text { Estradiol (pg/mL) }\end{array}$ & $\begin{array}{c}1.28 \\
19.19 \\
97\end{array}$ & 0.45 & $\begin{array}{c}0.13-1.08 \\
5.18-26.53 \\
1-147\end{array}$ \\
\hline
\end{tabular}

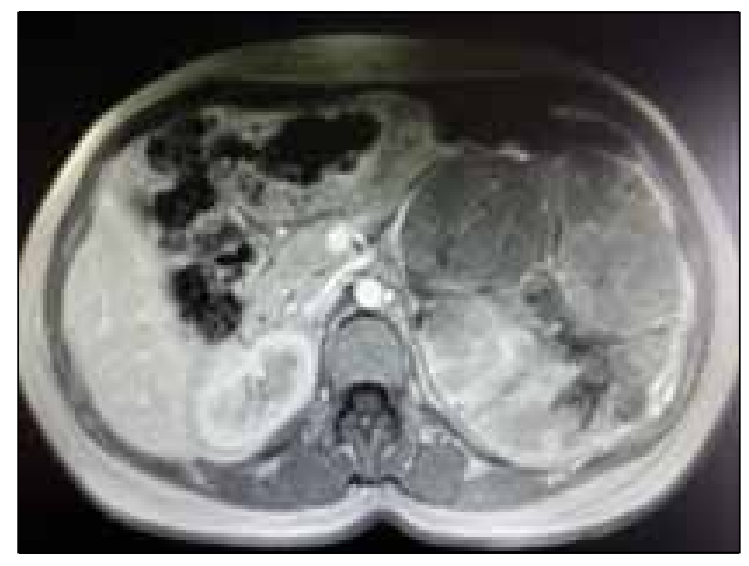

Fig. 2. Contrast-enhanced magnetic resonance image: Transverse plane.

observably regressed to their normal reference ranges. The patient was referred to medical oncology during the postoperative period. The medical oncologist started mitotane treatment and treatment is ongoing.

\section{Discussion}

Sex hormone-secreting tumours are more likely malignant. Feminization is more closely associated with malignancy rather than virilization. ${ }^{16}$ Feminizing ACCs are rare and constitute only $1 \%$ to $2 \%$ of all adrenocortical malignancies. ${ }^{7}$ High levels of DHEA-S are another marker for ACC, whereas decreased serum DHEA-S concentrations suggest benign adenoma. ${ }^{17}$ Androgen-secreting tumours can produce hirsutism and virilization in $90 \%$ to $100 \%$ of patients and amenorrhea in $40 \%$ to $60 \%$ of patients. ${ }^{18}$ Our patient had none of these symptoms, though her DHEA-S level was very high (>1500 ug/dL).

ACCs are generally detected incidentally; the CT and MRI are other diagnostic radiological modalities. F-fluorodeoxyglucose (FDG)-PET/CT is still considered complementary and not recommended for ACC workup. ${ }^{19}$ Although lesion detection is similar between PET/CT and $\mathrm{CT}, \mathrm{PET} / \mathrm{CT}$ may be preferred to assess chemotherapeutic response. ${ }^{20}$ When we reviewed the literature, we observed that only $25 \%$ to $30 \%$ of patients were in stage 1-2 (organconfined disease), while $70 \%$ were in stage $3-4$ (invasion beyond adrenal gland). ${ }^{19,21}$ Our patient was in stage 2 . Treatment alternatives consist of surgical treatment and/ or adjuvant chemotherapy and/or adjuvant radiotherapy. The most important step of curative treatment constitutes complete resection of primary or recurrent tumour. Even after larger surgical resection, many patients experience recurrence and distant metastases. ${ }^{9}$ Even among patients who had undergone radical surgery, local recurrence and metastasis were seen in nearly $80 \%$ of cases. ${ }^{21}$ Many studies have demonstrated favourable effects of tumour resection 


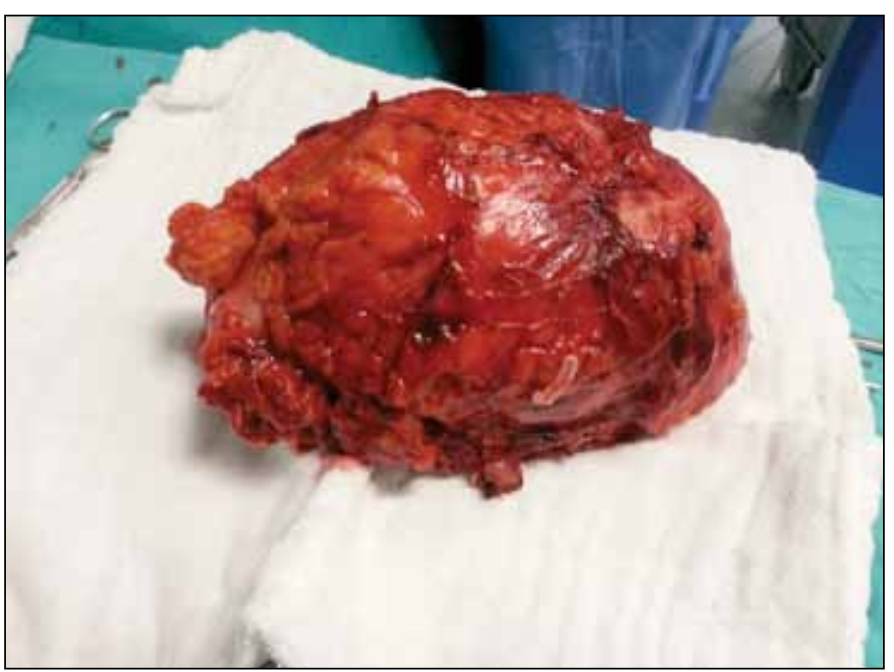

Fig. 3. Macroscopic view of en bloc specimen: an encapsulated mass with smooth contours weighing $1300 \mathrm{gr}$, with dimensions of $23 \times 18 \times 16 \mathrm{~cm}$.

on survival rates. Moreover, resection of recurrent tumours ensures palliation of hormonal symptoms in patients with functional ACC. ${ }^{22}$

Higher recurrence rates of ACCs have led the researchers to search for adjuvant treatment modalities. As adjuvant treatments, cytotoxic drugs, molecular targeted therapies, radiotherapy and other locally ablative modalities have been tried, with no promising outcomes. ${ }^{23}$ Mitotane is a synthetic derivative of the insecticide dichlorodiphenyltrichloroethane used for this purpose. Terzolo and colleagues ${ }^{24}$ conducted a retrospective multicentered study in Italy and Germany and associated higher recurrence-free and overall survival rates to adjuvant mitotane treatment in ACC patients whose tumours were completely resected without residual tumour as demonstrated by histopathological and radiological examinations.

In many studies, advanced stage tumour and incomplete surgical resection are the main factors associated with poor prognosis. Also, high grade, advanced age, hormone secretion, gender and large tumour size are correlated with poor prognosis. ${ }^{25}$ Bilimoria and colleagues ${ }^{26}$ reviewed 3928 patients. They found that the worse prognostic factors were: advanced age (>55), positive surgical margins, lymph node positivity, distant metastasis, and resection of adjacent organs. They also evaluated tumours according to size in two groups (smaller than $10 \mathrm{~cm}$ and larger than $10 \mathrm{~cm}$ in diameter); these sizes were not correlated with a poor prognosis.

Though precise histological criteria to define malignant adrenal masses are lacking, the histopathological factor most related to prognosis described by Weiss in 1984 is frequently used. The presence of 3 or more criteria from 9 histological criteria has been evaluated in favour of malignancy. ${ }^{27}$ In our patient, 4 of the 9 criteria were present, namely capsular invasion, cellular atypia, mitotic index $>5 / 50$ (56/50), and microscopic necrosis.

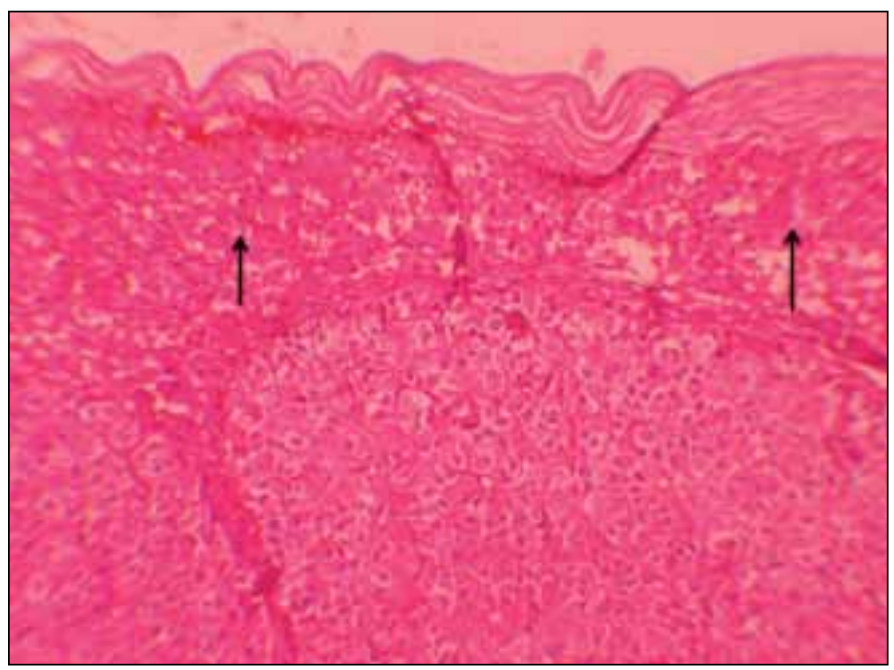

Fig. 4. Hematoxylin and eosin stain of the adrenal gland. Arrows: Adrenocortical carcinoma. Inferior: Residual rim of normal adrenal gland $(100 x)$.

Immunohistochemical assessment of the nuclear antigen $\mathrm{Ki}-67$ can be useful in the differential diagnosis between adrenocortical adenoma and carcinoma. Studies have demonstrated that a higher Ki-67 proliferation index is associated with poor prognosis and an inverse and significant correlation exists between this index and overall survival rate. ${ }^{23}$ In our patient, the $\mathrm{Ki}-67$ proliferation index was $11 \%$ to $13 \%$.

\section{Conclusion}

Sex hormone-secreting ACCs are very rarely seen in urology practice. We reviewed the literature and reported a case with the largest-sized non-metastasizing, androgen-producing but clinically silent ACC mass.

Competıng interests: The authors all declare no competing financial or personal interests.

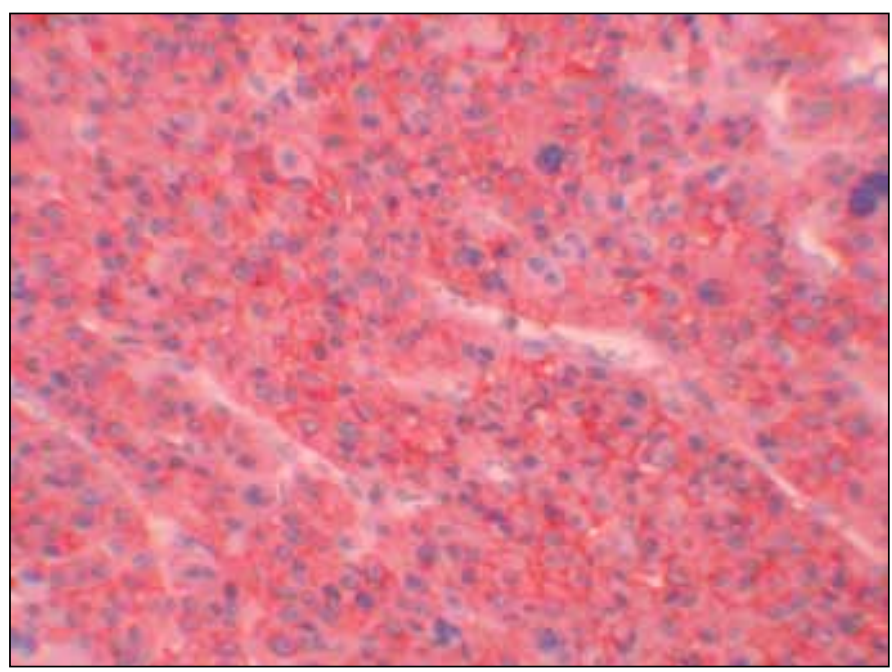

Fig. 5. Immunohistochemical stain: synaptophysin (100x). 
This paper has been peer-reviewed.

\section{References}

1. Allolio B, Fassnacht M. Clinical review: Adrenocortical carcinoma: Clinical update. J Clin Endocrinol Metab 2006;91:2027-37. http://dx.doi.org/10.1210/ic.2005-2639

2. Ferreira U, Nardi Pedro R, Matheus WE, et al. Open surgical treatment of right-sided adrenal carcinomas $>15$ cm. Urol Int 2007;78:46-9. httrp://dx.doi.org/10.1159/000096934

3. Kopf D, Goretzki PE, Lehnert H. Clinical management of malignant adrenal tumors. J Cancer Res Clin Oncol 2001;127:143-55. http://dx.doi.org/10.1007/s004320000170

4. Lughezzani $G$, Sun $M$, Perrotte $P$, et al. The European Network for the Study of Adrenal Tumors staging system is prognostically superior to the international union against cancer-staging system: A North American validation. Eur J Cancer 2010;46:713-9. http://dx.doi.org/10.1016/i.ejca.2009.12.007

5. Lerario AM, Moraitis A, Hammer GD. Genetics and epigenetics of adrenocortical tumors. Mol Cell Endocrinol 2014;386:67-84. http://dx.doi.org/10.1016/i.mce.2013.10.028

6. Alexandraki KI, Grossman AB. Adrenal incidentalomas: 'the rule of four'. Clin Med 2008;8:201-4. http:// dx.doi.org/10.7861/clinmedicine.8-2-201

7. Kidd MT, Karlin NJ, Cook CB. Feminizing adrenal neoplasms: Case presentations and review of the literature. J Clin Oncol 2011;29:127-30. http://dx.doi.org/10.1200/JC0.2010.31.4799

8. Almarzoug $A, A$ Asfar $S$, Hussain $S$, et al. Giant nonfunctioning adrenocortical carcinoma: A case report and review of the literature. BMC Res Notes 2014;7:769. http://dx.doi.org/10.1186/1756-0500-7-769

9. Icard $P$, Goudet $P$, Charpenay $C$, et al. Adrenocortical carcinomas: Surgical trends and results of a 253-patient series from the French Association of Endocrine Surgeons study group. World I Surg 2001;25:891-7. http://dx.doi.org/10.1007/s00268-001-0047-y

10. Fassnacht M, Allolio B. Clinical management of adrenocortical carcinoma. Best Pract Res Clin Endocrinol Metab 2009;23:273-89. http://dx.doi.org/10.1016/i.beem.2008.10.008

11. Miller BS, Doherty GM. Surgical management of adrenocortical tumours. Nat Rev Endocrino. 2014;10:28292. http://dx.doi.org/10.1038/nrendo.2014.26

12. Ayala-Ramirez $M$, Jasim $S$, Feng $L$, et al. Adrenocortical carcinoma: Clinical outcomes and prognosis of 330 patients at a tertiary care center. Eur J Endocrinol 2013;169:891-9. http://dx.doi.org/10.1530/ EJE-13-0519

13. Norton JA. Adrenal tumors. In Cancer: Principles and Practice of Oncology. $7^{\text {th }}$ edition. Edited by DeVita VT Jr, Hellman S, Rosenberg SA, Philedelphia, PA: Lippincott Williams Wilkins; 2005:1528-39.

14. Terzolo M, Angeli A, Fassnacht $M$, et al. Adjuvan mitotane treatment for adrenocortical carcinoma. N Engl J Med 2007;356:2372-80. http://dx.doi.org/10.1056/NEJMoa063360
15. Berruti A, Terzolo M, Pia A, et al. Mitotane associated with etoposide, doxorubicin, andcisplatin in the treatment of advanced adrenocortical carcinoma. Italian Group for the Study of Adrenal Cancer. Cancer 1998;83:2194-200. http://dx.doi.org/10.1002/(SICI) 1097-0142(19981115)83:10<2194::AIDCNCR19>3.3.C0;2-V

16. Advani A, Johnson SJ, Nicol MR, et al. Adult-onset hypogonadotropic hypogonadism caused by aberrant expression of aromatase in an adrenocortical adenocarcinoma. Endocr J 2010;57:651-6. http://dx.doi. org/10.1507/endocri.K10E-046

17. Fassnacht M, Kenn W, Allolio B. Adrenal tumors: How to establish malignancy? J Endocrinol Invest 2004;27:387-99. http://dx.doi.org/10.1007/BF03351068

18. Cordera F, Grant C, Van Heerden J, et al. Androgen-secreting adrenal tumors. Surgery 2003;134:874-80. http://dx.doi.org/10.1016/S0039-6060(03)00410-0

19. Phan AT. Adrenalcortical carcinoma review of current knowledge and treatment practices. Hematol Oncol Clin North Am 2007;21:489-507. http://dx.doi.org/10.1016/i.hoc.2007.04.007

20. Takeuchi S, Balachandran A, Habra MA, et al. Impact of 18F-FDG PET/CT on the management of adrenocortical carcinoma: analysis of 106 patients. Eur J Nucl Med Mol Imaging 2014;41:2066-73. http://dx.doi.org/10.1007/s00259-014-2834-3

21. Lafemina J, Brennan MF. Adrenocorticalcarcinoma: past, present, and future. I Surg Oncol 2012; 106:58694. http://dx.doi.org/10.1002/iso.23112

22. Schulick RD, Brennan MF. Long-term survival after complete resection and repeatresection in patients with adrenocortical carcinoma. Ann Surg Oncol 1999;6:719-26. http://dx.doi.org/10.1007/s10434999-0719-7

23. Ronchi CL, Kroiss M, Sbiera S, et al. EJE PRIZE 2014: Current and evolving treatment options in adrenocortical carcinoma: Where do we stand and where do we want to go? Eur J Endocrinol 2014;171:R1-R11. http://dx.doi.org/10.1530/EJE-14-0273

24. Terzolo M, Boccuzzi A, Bovio S, et al. Immunohistochemical assessment of Ki-67 in the differential diagnosis of adrenocortical tumors. Urology 2001;57:176-82. http://dx.doi.org/10.1016/500904295(00)00852-9

25. Kebebew E, Reiff E, Duh QY, et al. Extent of disease at presentation and outcome for adrenocortical carcinoma: Have we made progress? World J Surg 2006;30:872-8. http://dx.doi.org/10.1007/ s00268-005-0329-x

26. Bilimoria KY, Shen WT, Elarai D, et al. Adrenocortical carcinoma in the United States: Treatment utilization and prognostic factors. Cancer 2008;113:3130-6. http://dx.doi.org/10.1002/cncr.23886

27. Weiss LM. Comparative histologic study of 43 metastasizing and nonmetastasizing adrenocortical tumors. Am J Surg Pathol 1984;8:163-9. http://dx.doi.org/10.1097/00000478-198403000-00001

Correspondence: Dr. Ahmet Urkmez, Fatih Sultan Mehmet Research and Training Hospital, Department of Urology, Içerenkoy/Atasehir, Tr-34752 Istanbul, Turkey; ahmeturkmez@hotmail.com 